\title{
Effect of Lycopene and Tomato Products on Cholesterol Metabolism
}

\author{
P. Palozza ${ }^{a}$ A. Catalano ${ }^{a}$ R.E. Simone ${ }^{a} \quad$ M.C. Mele ${ }^{b} \quad$ A. Cittadini $^{a}$ \\ Institutes of a General Pathology and ${ }^{b}$ Biochemistry and Clinical Biochemistry, School of Medicine, \\ Catholic University, Rome, Italy
}

\section{Key Words}

Lycopene $\cdot$ Tomato $\cdot$ Cholesterol $\cdot$ Atherosclerosis .

3-Hydroxy-3-methylglutaryl coenzyme A reductase

\begin{abstract}
Background/Aims: Increased ingestion of tomato, containing lycopene, has been associated with a decreased risk for atherosclerosis, although the exact molecular mechanism is still unknown. Here we review the available evidence for a direct regulation of tomato lycopene on cholesterol metabolism using results from experimental and human studies. Results: In human macrophages lycopene dose dependently reduced intracellular total cholesterol. Such an effect was associated with a decrease in cholesterol synthesis through a reduction of 3-hydroxy-3-methylglutaryl coenzyme A reductase activity and expression, a modulation of lowdensity lipoprotein (LDL) receptor and acyl-coenzyme A:cholesterol acyltransferase activity. An increase in cholesterol efflux through an enhancement of ABCA1 and caveolin-1 expression was also observed. In animal models of atherosclerosis, lycopene and tomato products decreased plasma total cholesterol, LDL cholesterol and increased high-density lipoprotein cholesterol. In agreement with the experimental results, most human intervention trials analyzed show that dietary supplementation with lycopene
\end{abstract}

and/or tomato products reduced plasma LDL cholesterol dependently on the dose and the time of administration. Conclusions: Although lycopene and tomato products seem to possess direct hypocholesterolemic properties, more experimental studies are needed to better understand the mechanisms involved. There is also a need for more well-designed human dietary intervention studies to better clarify the role of lycopene as a hypocholesterolemic agent.

Copyright ๑ 2012 S. Karger AG, Basel

\section{Introduction}

Maintenance of cholesterol homeostasis is vital for healthy status and is achieved through a regulatory network consisting of genes involved in cholesterol synthesis, absorption, metabolism and elimination. Imbalance of cholesterol level leads to hypercholesterolemia, a predominant risk factor for atherosclerosis and associated coronary and cerebrovascular diseases [1-4]. The American Heart Association's recommendations are (no higher than) $200 \mathrm{mg} / \mathrm{dl}$ for total cholesterol levels while classifying 'high cholesterol' as at least $240 \mathrm{mg} / \mathrm{dl}$. 'Optimal' high-density lipoprotein (HDL) and low-density lipoprotein (LDL) cholesterol levels are at least $60 \mathrm{mg} / \mathrm{dl}$ and no higher than $100 \mathrm{mg} / \mathrm{dl}$, respectively.

\section{KARGER \\ Fax +4161306 1234 \\ E-Mail karger@karger.ch}

www.karger.com
(C) 2012 S. Karger AG, Basel

0250-6807/12/0612-0126\$38.00/0

Accessible online at:

www.karger.com/anm
P. Palozza

Institute of General Pathology, Catholic University, School of Medicine

Largo F. Vito 1

IT-00168 Rome (Italy)

Tel. +39 0630166 19, E-Mail p.palozza@rm.unicatt.it 
Cholesterol is derived from the uptake of plasma LDL via receptor-mediated endocytosis [5] as well as from the novo cellular synthesis [6]. Over accumulation of cholesterol in cells is avoided by maintaining a balance between these external and internal cholesterol sources. This balance is achieved through three separate processes. The first one involves the suppression of cholesterol synthesis within the cell by inhibition of the activity of the enzyme 3-hydroxy-3-methylglutaryl coenzyme A (HMG-CoA) reductase, which promotes the reductive deacylation of HMG-CoA to mevalonate [6]. The second one involves cholesterol activation of the enzyme acyl-coenzyme A:cholesterol acyltransferase (ACAT), favoring esterification and storage of excess cholesterol. The third one involves cholesterol suppression of the synthesis of LDL receptors, thus protecting the cells from excessive accumulation of cholesterol [5].

Control of cholesterol levels through therapeutic drugs have significantly reduced the risk of developing atherosclerosis and associated cardiovascular diseases [7-10]. Notably, statins, a class of cholesterol-lowering drugs inhibiting cholesterol synthesis, have been most widely prescribed for treating hypercholesterolemia and reducing cardiovascular diseases [8-10]. However, adverse effects associated with therapeutic drugs, such as myopathy, liver damages and potential drug-drug interaction, have been reported [11-15]. Therefore, the development of additional therapies for controlling cholesterol levels is warranted to reduce cardiovascular diseases. The potential for tomato and/or tomato products to prevent atherosclerosis is currently under investigation and a lot of emphasis has been placed on elucidating the role of lycopene, the most abundant carotenoid in ripe tomato, and its mechanism(s) of action.

Lycopene is a natural pigment synthesized by plants and microorganisms but not by animals, mainly present in tomato, processed tomato products and other fruits, such as watermelon, papaya, guava and pink grapefruit. It is responsible for the red color of many fruits and vegetables such as the tomato. It is a carotenoid, anacyclic isomer of $\beta$-carotene and has no vitamin A activity $[16$, 17]. It is a highly unsaturated, straight-chain hydrocarbon containing eleven conjugated and two nonconjugated double bonds (fig. 1). Because of the presence of double bonds in the structure of lycopene, it can exist in both the cis- and trans-isomeric forms. In nature, lycopene is present primarily in all trans-isomeric forms [18]. However, it can undergo mono or poly isomerization by light, thermal energy and chemical reactions to its cis-isomeric forms. It can also undergo oxidative, thermal and photo-

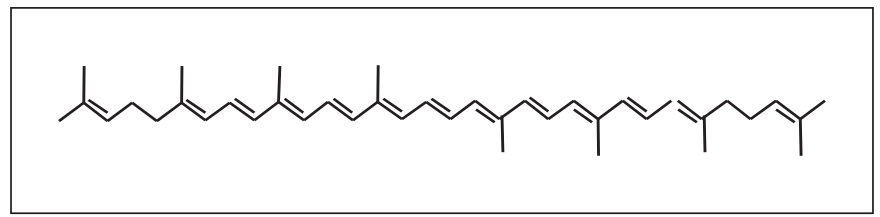

Fig. 1. Chemical structure of lycopene.

degradation [19]. Studies have shown lycopene to be stable under the conditions of thermal processing and storage [20]. It is the most predominant carotenoid in human plasma. Tomatoes and tomato-based foods account for more than $85 \%$ of all the dietary sources of lycopene. Lycopene content in tomato ranges from 8.8 to $42 \mu \mathrm{g} / \mathrm{g}$ wet weight. Lycopene absorption from dietary sources is influenced by several factors including the break-up of the food matrix containing lycopene, cooking temperatures and the presence of lipids and other lipid-soluble compounds including other carotenoids [21]. Absorption of lycopene is similar to that of lipids and is absorbed across the gastrointestinal tract. Lycopene and other carotenoids are transported from the intestinal mucosa to the general circulation via the lymphatic system. In the blood, lycopene is transported mainly by LDL. In general, 10$30 \%$ of the dietary lycopene is absorbed by humans. Liver, seminal vesicles and prostate tissue are the primary sites of lycopene accumulation in vivo [22].

The potential antiatherogenic role of lycopene has been ascribed mainly to its antioxidant capacity, which is related to the prevention of LDL oxidation [23]. Recently, a new mechanism involving a regulation of cholesterol metabolism by carotenoids has been evoked [24]. This seems to be sustained by the observation that lycopene shares similar initial synthetic pathways with cholesterol, which is synthesized in animal but not in plant cells. Moreover, increasing evidence from clinical trials show that lycopene supplementation is effective in reducing LDL cholesterol. Such an effect is comparable to that of low doses of statins in patients with slightly elevated cholesterol levels.

This review focuses on the role of tomato lycopene and tomato products in controlling hypercholesterolemia. In particular, recent data on the regulation of molecular pathways involved in cholesterol metabolism exerted by lycopene and tomato products in isolated cells as well as in animal models will be discussed. Moreover, the evidence for modulatory effects of lycopene and tomato on plasma levels of cholesterol, as evidenced from interven- 
tion trials, is summarized. A clear understanding of the molecular mechanisms of action of lycopene is crucial in the valuation of this molecule as a potential hypocholesterolemic agent.

\section{In vitro Studies}

The reduction of intracellular cholesterol by lycopene and tomato derivatives has been associated with a decrease in cholesterol synthesis through an inhibition of HMG-CoA reductase activity and expression, a modulation of LDL receptor and ACAT activity (fig. 2). The studies evidencing such mechanisms are described below.

\section{Inhibition of Cholesterol Synthesis}

The committed step in the biosynthesis of cholesterol and isoprenoids is catalyzed by HMG-CoA reductase, which promotes the deacylation of HMG-CoA to mevalonate $[25,26]$. This pathway produces numerous bioactive signaling molecules, including farnesyl pyrophosphate and geranylgeranyl pyrophosphate, which regulate transcriptional and post-transcriptional events that affect various biological processes, including changes in proteins involved in the cholesterol metabolism, such as ABCA1 and caveolin-1 [25]. The activity of HMG-CoA reductase in animal cells has been shown to be sensitive to negative regulation by both sterols and nonsterol products of the mevalonate pathway $[6,27]$. Increasing evidence suggests that lycopene may inhibit cholesterol synthesis in human macrophages by inhibiting HMG-CoA reductase activity [28] and expression [29]. In the J-774 A.1 macrophage cell line, the cellular cholesterol synthesis from $\left[{ }^{3} \mathrm{H}\right]$-acetate, but not from $\left[{ }^{14} \mathrm{C}\right]$ mevalonate was suppressed by $63 \%$ and by $73 \%$ following cell incubation with $\beta$-carotene or lycopene $(10 \mu \mathrm{M})$, respectively. The increased potency of lycopene over $\beta$-carotene to inhibit cholesterol synthesis seems to be related to the enhanced uptake of lycopene over $\beta$-carotene by macrophages. It has been suggested that lycopene may inhibit cholesterol synthesis at the post-transcriptional level, whereas cholesterol regulates HMG-CoA reductase gene transcription and statins are competitive inhibitors of this enzyme [28]. In a recent paper, we demonstrated that lycopene may reduce intracellular levels of cholesterol in human THP-1 macrophages [29]. This effect was accompanied by a decrease in the expression of HMG-CoA reductase and by an enhancement of cholesterol efflux. The last event occurred through a cascade involving RhoA inactivation and peroxisome proliferator-activated receptor

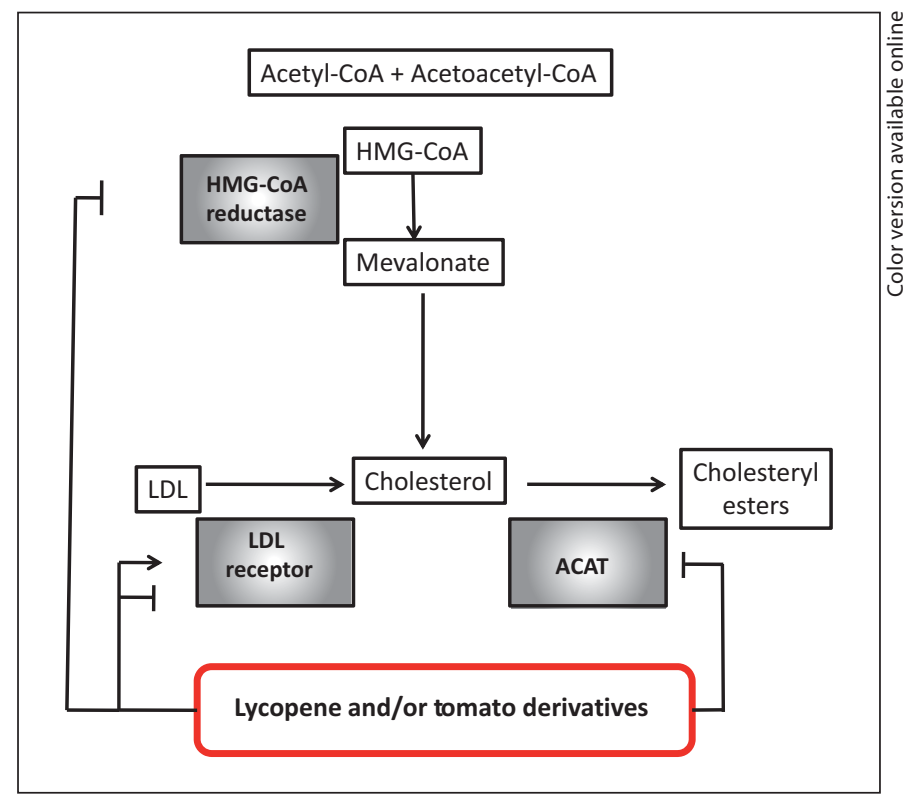

Fig. 2. Possible mechanisms implicated in the reduction of intracellular cholesterol by lycopene and tomato derivatives: decrease in cholesterol synthesis through inhibition of HMG-CoA reductase activity and expression, modulation of LDL receptor and inhibition of ACAT activity.

gamma (PPAR $\gamma)$ and liver X receptor $\alpha(\mathrm{LXR} \alpha)$ activation (fig. 3). In fact, key targets of PPAR $\gamma$ and LXR $\alpha$ activation are the ATP-binding cassette $\mathrm{ABC}$ proteins, including $A B C A 1$, and the caveolin family proteins, including cav-1. ABCA1 controls the rate-limiting step in cellular cholesterol and phospholipid efflux to apoA1 [30]. On the other hand, cav-1 expression is associated with an enhancement of cholesterol efflux [31-33] since it increases cholesterol association with lipid rafts. We demonstrated that lycopene, at concentrations within the range which activated PPAR $\gamma$ and $\mathrm{LXR} \alpha$ receptors, dose dependently induced the expression of both ABCA1 and cav-1 in THP-1 macrophages. The increase in ABCA1 by lycopene is interesting since ABCA1 is also suggested to be a carotenoid transporter [34]. Moreover, PPAR $\gamma$ ligands are reported to induce an up-regulation of both ABCA1 and cav-1 [35-37]. It has recently been shown that $\beta$-cryptoxanthin induces ABCA1 and ABCG1 mRNAs and $A B C A 1$ protein in macrophages by a mechanism involving retinoic acid receptors.

\section{Modulation of LDL Receptor Activity}

The inhibition of HMG-CoA reductase activity in mammalian cells by excess cholesterol is associated with 
Fig. 3. Lycopene inhibition of molecular pathways involved in cholesterol metabolism. The committed step in the biosynthesis of cholesterol and isoprenoids is catalyzed by HMG-CoA reductase, which promotes the deacylation of HMG-CoA to mevalonate. This pathway produces farnesyl pyrophosphate (FPP) and geranylgeranyl pyrophosphate (GGPP), which regulate RhoA, PPAR $\gamma$ and $\operatorname{LXR} \alpha$ activation. Key targets of PPAR $\gamma$ and LXR $\alpha$ activation are the ATP-binding cassette ABC proteins, including ABCA1, and the caveolin family proteins, including cav-1.

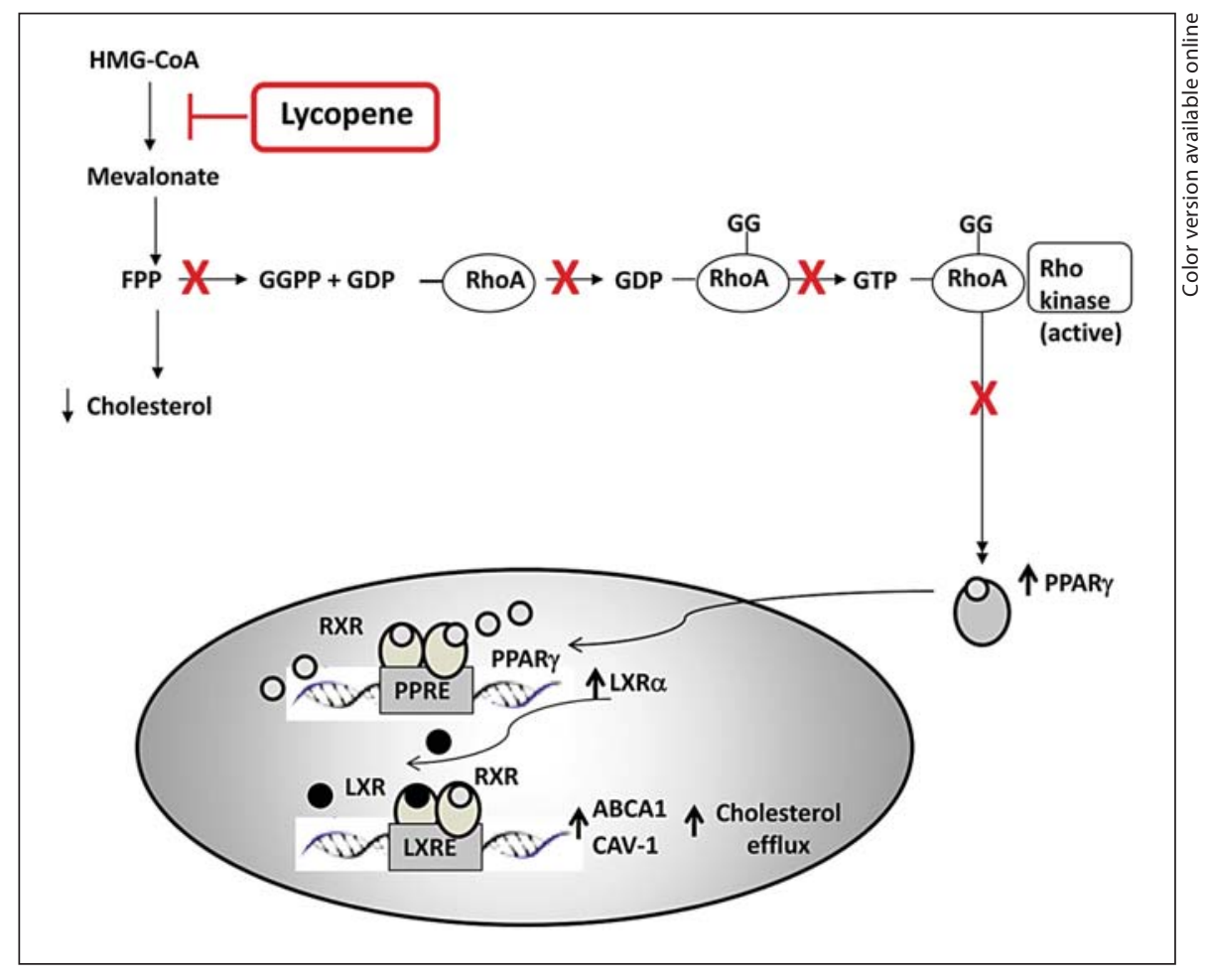

reduced LDL receptor activity secondary to sterol-induced inhibition of the LDL receptor gene transcription [38]. On the other hand, it has been demonstrated that in carotenoids-enriched cells the LDL receptor synthesis is not inhibited [28]. The results of Fuhrman et al. [28] demonstrated an increased LDL uptake by macrophages which were enriched with either lycopene or $\beta$-carotene, in contrast to the reduced uptake of LDL by cholesterolenriched macrophages. Inhibitors of cholesterol biosynthesis are known to reduce serum cholesterol concentrations by enhancing the removal of serum LDL, secondary to the activation of the LDL receptors [39]. Thus, inhibition of HMG-CoA reductase by carotenoids, similarly to some statins, probably triggers a coordinate increased expression of the genes which code for the LDL receptor. Such an increase was also demonstrated for other plantderived isoprenoids, such as tocotrienols [40-42].

\section{Modulation of ACAT}

Compounds contained in ripe tomato, such as esculeoside A and esculeogenin A [43,44], have been shown to exhibit similar inhibitory effects on cholesterol ester accumulation in human monocyte-derived macrophages (HMDM) and on atherogenesis in apoE-deficient mice [44]. Moreover, recent evidence suggests that retinoids
$[45,46]$ are able to modulate ACAT activity. However, at the moment, few data are available on a direct modulation of ACAT by lycopene. Lycopene was found to decrease the synthesis of cholesterol esters in HMDM incubated without LDL or with oxidized LDL [47]. These results are broadly similar to those obtained in HMDM using comparable concentrations of FeAOX-6, a synthetic compound that combines the antioxidant structural features of vitamin $\mathrm{E}$ and lycopene. The reduction in cholesterol ester synthesis by FeAOX-6 was extremely marked in the presence of oxidized LDL [48]. The results of the in vitro studies are summarized in table 1 .

\section{Animal Studies}

$\mathrm{Hu}$ et al. [49] evaluated the antiatherogenic effect of lycopene in rabbits fed a high-fat diet. Lycopene was supplemented intragastrically at a dose of $4-12 \mathrm{mg} / \mathrm{kg}$ for 4 and 8 weeks. The carotenoid markedly reduced the formation of atherosclerotic plaques in the aorta from rabbits in their study. Such an effect was accompanied by a decrease in the levels of total cholesterol, total triacylglycerol, LDL cholesterol, malondialdehyde, oxidized LDL and interleukin-1, and by an increase of total antioxidant 
Table 1. Modulatory effects of lycopene, lycopene derivatives and tomato products on cholesterol pathways in cell culture studies

\begin{tabular}{llc}
\hline Treatment & Effects & Ref. \\
& & No. \\
\hline Lycopene $(2.5-10 \mu \mathrm{M})$ & $\downarrow$ HMG-CoA reductase activity & 28 \\
& $\uparrow$ LDL receptor activity & \\
Lycopene $(0.5-2 \mu \mathrm{M})$ & $\downarrow$ HMG-CoA reductase expression & 29 \\
& $\begin{array}{l}\text { RhoA inactivation } \\
\end{array}$ & \\
& $\uparrow$ PPAR expression & \\
& $\uparrow$ LXR $\alpha$ expression & \\
& $\uparrow$ ABCA1 expression & \\
Esculeoside A & $\uparrow$ Caveolin-1 expression & \\
Esculeogenin A & & 44 \\
Lycopene $(10-100 \mu \mathrm{M})$ & $\downarrow$ ACAT activity & 47 \\
Lycopene $(10 \mu \mathrm{M})$ & $\downarrow$ Synthesis of cholesterol ester & \\
FeAOX-6 $(20 \mu \mathrm{M})$ & $\downarrow$ Synthesis of cholesterol esters & 48 \\
\hline
\end{tabular}

capacity and nitric oxide. Interestingly, these effects were more remarkable than those obtained by fluvastatin administration $(10 \mathrm{mg} / \mathrm{kg})$.

In the same animal model, supplementation with three doses of lycopene in the chow for 12 weeks dose dependently decreased diet-induced serum total cholesterol and LDL cholesterol levels and increased HDL cholesterol [50]. In contrast, supplementation with a lycopene-enriched tomato extract $(15 \mathrm{mg} / \mathrm{kg}$ body weight/ day lycopene) in the diet for 16 weeks had no effect on plasma cholesterol levels in Watanabe Heritable Hyperlipidemic rabbits [51]. The reason for the lack of effects of lycopene in these rabbits may originate in defective LDL receptors [52]. Since lycopene is transported in the blood mainly in LDL particles, a functional LDL receptor may be essential to obtain cardiovascular beneficial effects of lycopene.

Recently, Lorenz et al. [53] studied the effects of lycopene on diet-induced increase in serum lipid levels and the initiation of atherosclerosis in New Zealand White (NZW) rabbits. Lycopene (in the form of lycopene beadlets), at the dose of $5 \mathrm{mg} / \mathrm{kg}$ body weight/day, was administered for a period of 4 weeks. Compared to the high cholesterol and the placebo group, the animal group treated with lycopene beadlets was associated with a significant reduction by about $50 \%$ in total cholesterol and LDL cholesterol serum levels. The number of cholesteryl esters in the aorta was also significantly decreased by lycopene.
Mulkalwar et al. [54] tested the hypolipidemic and antioxidant effect of pure lycopene powder in hyperlipidemic NZW rabbits. The carotenoid was administered at the dose of $10 \mathrm{mg} / \mathrm{kg}$ body weight/day for 6 weeks. There was a significant decrease in the level of serum total cholesterol and LDL cholesterol and an increase in serum HDL cholesterol following the addition of lycopene to a high-fat diet.

Basuny et al. [55] investigated the effects of concentrated tomato lycopene (100,200, 400 and $800 \mathrm{ppm})$, grade lycopene $(200 \mathrm{ppm})$ and butylated hydroxytoluene (200 ppm) on serum lipid contents (total lipids, total cholesterol, HDL cholesterol and LDL cholesterol), oxidative biomarkers (glutathione peroxidase and malondialdehyde), liver (aspartate aminotransferase, alanine aminotransferase and alkaline phosphatase activities) and kidney (uric acid, urea and creatinine) function parameters. The compounds were administered to rats fed a hypercholestrolemic diet for 10 weeks by stomach tube. The groups of rats fed with a high-fat diet and given tomato orally in different concentrations induced significant decreases in serum total cholesterol. A similar decrease was observed following supplementation of grade lycopene, indicating that lycopene can lower the concentration of serum total cholesterol. Tomato lycopene also prevented the increase in total and LDL serum cholesterol in highcholesterol-fed rats. A similar effect was also reported by Kuhad et al. [56] in diabetic mice fed with lycopene at different doses (1,2 and $4 \mathrm{mg} / \mathrm{kg}$ body weight) for $4-8$ weeks. Moreover, rats fed a high-fat diet with tomato lycopene recorded the highest concentration of HDL [56].

The therapeutic effect of lycopene-rich tomato juice against evoked cardiac disorders in rats fed on fried potato in oxidized frying cotton seed oil $(20 \% \mathrm{w} / \mathrm{w})$ for 4 weeks was studied using lycopene at a daily dose of $1 \mathrm{mg} /$ $\mathrm{kg}$ body weight [57]. The obtained results revealed that feeding on fried potato in deep oxidized frying oil induced a notable increase in lipid profiles and LDL cholesterol associated with a marked elevation in specific heart enzymes, LDL, CK, ALT and AST activities. These biochemical alterations ameliorated when lycopene was administered to rats fed fried potato in oxidized frying oil. Lycopene-rich tomato juice induced a significant decrease in total lipids, total cholesterol, triglycerides and phospholipids as well as LDL cholesterol and a marked elevation in HDL cholesterol. These effects may be due to the ability of lycopene in protecting LDL from oxidation, to its role in inhibiting HMG-CoA reductase activity and to up-regulate LDL receptor activity in macrophages $[58,59]$ as well as to its powerful efficacy in neutralizing free radicals. 
Table 2. Modulatory effects of lycopene and tomato products on cholesterol metabolism in animal studies

\begin{tabular}{|c|c|c|c|}
\hline Treatment & Animal model & Effects & $\begin{array}{l}\text { Ref. } \\
\text { No. }\end{array}$ \\
\hline $\begin{array}{l}\text { Lycopene } \\
\text { ( } 4-12 \mathrm{mg} / \mathrm{kg} \text { for } 4 \text { and } 8 \text { weeks) }\end{array}$ & rabbits & $\begin{array}{l}\downarrow \text { serum total cholesterol } \\
\downarrow \text { serum total triacylglycerol } \\
\downarrow \text { serum LDL-cholesterol } \\
\downarrow \text { serum malondialdehyde } \\
\downarrow \text { ox-LDL } \\
\downarrow \text { IL-1 } \\
\uparrow \text { total antioxidant capacity } \\
\uparrow \text { nitric oxide } \\
\downarrow \text { atherosclerotic plaques }\end{array}$ & 49 \\
\hline $\begin{array}{l}\text { Lycopene } \\
(42.6-127.8 \mathrm{ppm})\end{array}$ & rabbits & $\begin{array}{l}\downarrow \text { serum total cholesterol } \\
\downarrow \text { serum LDL-cholesterol } \\
\uparrow \text { serum HDL cholesterol }\end{array}$ & 50 \\
\hline $\begin{array}{l}\text { Lycopene } \\
\text { (12 mg/kg for } 16 \text { weeks) }\end{array}$ & WWHL rabbits & no changes in serum total cholesterol & 51 \\
\hline $\begin{array}{l}\text { Lycopene } \\
\text { ( } 5 \mathrm{mg} / \mathrm{kg} \text { for } 4 \text { weeks) }\end{array}$ & NZW rabbits & $\begin{array}{l}\downarrow \text { serum total cholesterol } \\
\downarrow \text { serum LDL-cholesterol } \\
\downarrow \text { serum cholesteryl esters }\end{array}$ & 53 \\
\hline $\begin{array}{l}\text { Lycopene } \\
\text { (10 mg/kg for } 6 \text { weeks) }\end{array}$ & NZW rabbits & $\begin{array}{l}\downarrow \text { serum total cholesterol } \\
\downarrow \text { serum LDL-cholesterol } \\
\uparrow \text { serum HDL cholesterol }\end{array}$ & 54 \\
\hline $\begin{array}{l}\text { Tomato lycopene } \\
\text { (100-800 ppm for } 10 \text { weeks) } \\
\text { or } \\
\text { Pure lycopene } \\
\text { ( } 200 \text { ppm for } 10 \text { weeks) }\end{array}$ & rats & $\begin{array}{l}\downarrow \text { serum total cholesterol } \\
\downarrow \text { serum LDL-cholesterol }\end{array}$ & 55 \\
\hline $\begin{array}{l}\text { Lycopene } \\
\text { (1-4 mg/kg for } 4-8 \text { weeks) }\end{array}$ & diabetic mice & $\begin{array}{l}\downarrow \text { serum total cholesterol } \\
\downarrow \text { serum LDL-cholesterol } \\
\uparrow \text { serum HDL cholesterol }\end{array}$ & 56 \\
\hline $\begin{array}{l}\text { Tomato juice } \\
\text { (containing } 1 \mathrm{mg} / \mathrm{kg} \\
\text { lycopene for } 4 \text { weeks) }\end{array}$ & rats & $\begin{array}{l}\downarrow \text { total lipids } \\
\downarrow \text { serum total cholesterol } \\
\downarrow \text { serum LDL-cholesterol } \\
\uparrow \text { serum HDL cholesterol }\end{array}$ & 57 \\
\hline AIDM & ApoE*3Leiden transgenic mice & $\begin{array}{l}\downarrow \text { plasma LDL-cholesterol } \\
\downarrow \text { plasma VLDL-cholesterol } \\
\downarrow \text { atherosclerotic plaques }\end{array}$ & 60 \\
\hline $\begin{array}{l}\text { Lycopene and vitamin E } \\
\text { (dl- } \alpha \text {-tocopheryl-acetate) }\end{array}$ & Japanese quails & $\begin{array}{l}\downarrow \text { serum cholesterol } \\
\downarrow \text { yolk cholesterol }\end{array}$ & 61 \\
\hline
\end{tabular}

WWHL = Watanabe heritable hyperlipidemic.

A recent study showed that a mixture containing lycopene, fish oil, resveratrol, catechin, $\mathrm{d}$ - $\alpha$-tocopherol and vitamin C (AIDM) reduces lipid and inflammatory risk factors of CVD in male human C-reactive protein transgenic mice [60]. Moreover, in a long-term treatment, AIDM strongly attenuates the development of atheroscle- rosis in female $\mathrm{ApoE}^{*} 3$ Leiden transgenic mice. In such a model, plasma cholesterol in very LDL and LDL was strongly reduced. Moreover, supplementation of Japanese quails with dietary lycopene (100 $\mathrm{mg} / \mathrm{kg}$ lycopene) and vitamin $\mathrm{E}$ (250 mg dl- $\alpha$-tocopheryl-acetate/kg diet), separately or as a combination, reduced serum and yolk cho- 
lesterol concentrations and improved antioxidant status [61]. The magnitude of the responses was greatest with the combination of lycopene and vitamin $\mathrm{E}$, rather than with each supplement separately. The results of the animal studies are summarized in table 2 .

\section{Human Studies}

In agreement with the experimental observations, dietary supplementation of lycopene $(60 \mathrm{mg} /$ day) to 6 men for a 3 -month period resulted in a significant $14 \%$ reduction in their plasma LDL cholesterol concentrations [28]. Supplementation with tomato extract capsules (4 mg lycopene) daily for 6 months decreased total cholesterol and LDL cholesterol levels in postmenopausal women [62]. Moreover, a reduction in LDL cholesterol to $17 \%$ by tomato juice has been reported [63]. In addition, a recent meta-analysis study [64] has found that lycopene may help keep cholesterol as well as blood pressure within healthy ranges. In the study, researchers identified 12 studies lasting at least 2 weeks in duration which involved supplementing with lycopene to help with high cholesterol levels and high blood pressure. The review found that at least $25 \mathrm{mg}$ per day of lycopene (obtained through both diet and supplementation) elicited beneficial health effects, helping lower total cholesterol levels by an average of $7.55 \mathrm{mg} / \mathrm{dl}(\mathrm{p}=0.02)$. A 2003 study showed an average $18.5 \mathrm{mg} / \mathrm{dl}$ decrease (9\% decrease, $202-183.5 \mathrm{mg} / \mathrm{dl}$ ) with up to $35 \mathrm{mg}$ per day [65].

In a randomized, crossover dietary intervention study, 19 healthy human subjects consumed lycopene from traditional tomato products and nutritional supplements for 1 week. The levels of lycopene consumption ranged from 20 to $150 \mathrm{mg}$ per day. Lycopene was observed to be absorbed readily from all dietary sources, resulting in significant increase in serum lycopene levels and lower levels of lipid, protein and DNA oxidation [66]. In the same study, although there were no changes in serum total cholesterol and LDL and HDL cholesterols, serum lipid peroxidation and LDL cholesterol oxidation were signifi- levels impacted on the results of MDA and FRAP antioxidant tests [69].

In the study of Bose et al. [70], no hypocholesterolemic effect was observed in CHD subjects supplemented with $200 \mathrm{~g}$ of ripe tomatoes (cooked) every day for a period of 60 days. This may be because tomato may not be so effective in inhibiting HMG-CoA reductase in a hyperlipidemic environment, which persists in CHD patients.

\section{Conclusions and Future Directions}

From the data presented lycopene and tomato products seem to possess direct hypocholesterolemic properties, however further studies are required to gain a better understanding of the role of lycopene in regulating cholesterol metabolism. Although the epidemiological studies conducted so far provide convincing evidence for the role of lycopene in protecting against heart disease, there is a need for more clinical studies to better establish the relationship between lycopene intake and cholesterol levels. Future research should focus on interactions of lycopene with other carotenoids. It is quite likely that lycopene acts with other tomato carotenoids to exert its biological activity. Numerous other potentially beneficial compounds are present in tomatoes and, possibly, complex interactions among multiple components may contribute to the hypocholesterolemic properties of tomatoes. An improved understanding of lycopene metabolism and the biological significance/functions of its different isomers and metabolites is also critical to elucidate mechanisms whereby this compound may exert hypocholesterolemic effects. There is also a need for more human dietary intervention studies. They should take into consideration subject selection, specific markers of analysis, metabolism and isomerization of lycopene, interaction with other antioxidants, dose and time of treatment. cantly decreased as the serum lycopene levels increased [67].

Conversely, no effects on blood lipid levels were obtained after supplementation with a tomato extract containing $15 \mathrm{mg}$ lycopene daily for 8 weeks in mild hypertensive patients [68]. Moreover, the inclusion of watermelon or tomato juice, containing $20 \mathrm{mg}$ lycopene, did not affect plasma lipid concentrations or the antioxidant status of healthy subjects. However, plasma cholesterol

References

Ann Nutr Metab 2012;61:126-134

\footnotetext{
1 Steinberg D: Thematic review series: the pathogenesis of atherosclerosis. An interpretive history of the cholesterol controversy: part II: the early evidence linking hypercholesterolemia to coronary disease in humans. J Lipid Res 2005;46:179-190.

-2 Ballantyne C, Arroll B, Shepherd J: Lipids and CVD management: towards a global consensus. Eur Heart J 2005;26:2224-2231.

-3 Meagher EA: Addressing cardiovascular risk beyond low-density lipoprotein cholesterol: the high-density lipoprotein cholesterol story. Curr Cardiol Rep 2004;6:457-463.
}

Palozza/Catalano/Simone/Mele/ Cittadini 
4 Ginsberg HN, Stalenhoef AF: The metabolic syndrome: targeting dyslipidaemia to reduce coronary risk. J Cardiovasc Risk 2003;10: 121-128.

-5 Brown MS, Goldstein JL: A receptor-mediated pathway for cholesterol homeostasis. Science 1986;232:34-47.

6 Brown MS, Goldstein JL: Multivalent feedback regulation of HMG CoA reductase, a control mechanism coordinating isoprenoid synthesis and cell growth. J Lipid Res 1980; 21:505-517.

7 Stacy TA, Egger A: Results of retrospective chart review to determine improvement in lipid goal attainment in patients treated by high-volume prescribers of lipid-modifying drugs. J Manag Care Pharm 2006;12:745751.

-8 Ray KK, Cannon CP, Ganz P: Beyond lipid lowering: what have we learned about the benefits of statins from the acute coronary syndromes trials? Am J Cardiol 2006;98:1825.

-9 Khush KK, Waters DD: Effects of statin therapy on the development and progression of heart failure: mechanisms and clinical trials. J Card Fail 2006;12:664-674.

10 Clearfield M: Statins and the primary prevention of cardiovascular events. Curr Atheroscler Rep 2006:8:390-396.

11 Talbert RL: Safety issues with statin therapy. J Am Pharm Assoc 2003;46:479-488.

12 Parra JL, Reddy KR: Hepatotoxicity of hypolipidemic drugs. Clin Liver Dis 2003;7:415433.

-13 Kiortsis DN, Filippatos TD, Mikhailidis DP, Elisaf MS, Liberopoulos EN: Statin-associated adverse effects beyond muscle and liver toxicity. Atherosclerosis 2007;195:7-16.

- 14 Trifiro G: Drug-drug interactions and statin therapy. South Med J 2006;99:1325-1326.

15 Neuvonen PJ, Niemi M, Backman JT: Drug interactions with lipid lowering drugs: mechanisms and clinical relevance. Clin Pharmacol Ther 2006;80:565-581.

- 16 Rao AV, Agarwal S: Role of antioxidant lycopene in cancer and heart disease. J Am Coll Nutr 2000;19:563-569.

17 Stahl W, Sies H: Lycopene: a biologically important carotenoid for humans? Arch Biochem Biophys 1996;336:1-9.

18 Clinton SK: Lycopene: chemistry, biology, and implications for human health and disease. Nutr Rev 1998;1:35-51.

-19 Agarwal S, Rao AV: Carotenoids and chronic diseases. Drug Metab Drug Interact 2000; 17:189-210.

-20 Agarwal A, Shen H, Agarwal S, Rao A: Lycopene content of tomato products: its stability, bioavailability and in vivo antioxidant properties. J Med Food 2001;4:9-15.

-21 Rao AV, Ray MR, Rao LG: Lycopene. Adv Food Nutr Res 2006;51:99-164.
22 Zaripheh S, Erdman JW Jr: The biodistribution of a single oral dose of $\left[{ }^{14} \mathrm{C}\right]$-lycopene in rats prefed either a control or lycopene rich diet. J Nutr 2005;135:2212-2218.

23 Rao AV: Lycopene tomatoes and the prevention of coronary heart disease. Exp Biol Med 2002;227:908-913.

24 Heber D, Lu QY: Overview of mechanism of action of lycopene. Exp Biol Med 2002;227: 920-923.

25 Edwards PA, Ericsson J: Sterols and isoprenoids: signaling molecules derived from the cholesterol biosynthetic pathway. Annu Rev Biochem 1999;68:157-185.

26 Istvan ES, Deisenhofer J: Structural mechanism for statin inhibition of HMG-CoA reductase. Science 2001;292:1160-1164.

27 Bilheimer DW, Grundy SM, Brown MS Goldstein JL: Mevinolin and colestipol stimulate receptor-mediated clearance of low density lipoprotein from plasma in familial hypercholesterolemia heterozygote. Proc Natl Acad Sci USA 1989;80:4142-4228.

28 Fuhrman B, Elis A, Aviram M: Hypocholesterolemic effect of lycopene and beta-carotene is related to suppression of cholesterol synthesis and augmentation of LDL receptor activity in macrophages. Biochem Biophys Res Commun 1997;233:658-662.

29 Palozza P, Simone R, Catalano A, Monego G, Barini A, Mele MC, Parrone N, Trombino S, Picci N, Ranelletti FO: Lycopene prevention of oxysterol-induced proinflammatory cytokine cascade in human macrophages: inhibition of NF-кB nuclear binding and increase in PPAR $\gamma$ expression. J Nutr Biochem 2011; 22:259-268.

30 Oram JF: ATP-binding cassette transporter $\mathrm{A} 1$ and cholesterol trafficking. Curr Opin Lipidol 2002;13:373-381.

-31 Gargalovic P, Ladislav D: Caveolins and macrophage lipid metabolism. Lipid Res 2003;44:11-21

32 Fielding CJ, Fielding PE: Caveolae and intracellular trafficking of cholesterol. Adv Drug Deliv Rev 2001;49:251-264.

-33 Hu Q, Zhang XJ, Liu CX, Wang XP, Zhang Y: PPAR $\gamma 1$-induced caveolin-1 enhances cholesterol efflux and attenuates atherosclerosis in apolipoprotein E-deficient mice. J Vasc Res 2010;47:69-79.

34 During A, Dawson HD, Harrison EH: Carotenoid transport is decreased and expression of the lipid transporters SR-BI, NPC1L1, and ABCA1 is downregulated in Caco- 2 cells treated with ezetimibe. J Nutr 2005; 135 : 2305-2312.

35 Lazar MA: Progress in cardiovascular biology: PPAR for the course. Nat Med 2001; 23-24.

- 36 Burgermeister E, Tencer L, Liscocitch M: Peroxisome proliferator-activated receptorgamma upregulates caveolin-1 and caveolin-2 expression in human carcinoma cells. Oncogene 2003;22:3888-3900.
-37 Llaverias G, Vazquez-Carrera M, Sanchez RM, Noe V, Ciudad CJ, Laguna JC, Alegret M: Rosiglitazone upregulates caveolin-1 expression in THP-1 cells through a PPAR-dependent mechanism. J Lipid Res 2004;45: 2015-2024.

38 Wang X, Sato R, Brown MS, Hua X, Goldstein JL: SREBP-1, a membrane-bound transcription factor released by sterol-regulated proteolysis. Cell 1994;77:53-62.

39 Ness GC, Zhao Z, Lopez D: Inhibitors of cholesterol biosynthesis increase hepatic lowdensity lipoprotein receptor protein degradation. Arch Biochem Biophys 1996;325: 242-248.

40 Parker RA, Pearce BC, Clark RW, Gordon DA, Wright JJ: Tocotrienols regulate cholesterol production in mammalian cells by post-transcriptional suppression of 3-hydroxy-3-methylglutaryl-coenzyme A reductase. J Biol Chem 1993;268:11230-11238.

41 Elson CE: Suppression of mevalonate pathway activities by dietary isoprenoids: protective roles in cancer and cardiovascular disease. J Nutr 1995;125:1666-1672.

42 Pearce BC, Parker RA, Deason ME, Qureshi AA, Wright JJ: Hypocholesterolemic activity of synthetic and natural tocotrienols. J Med Chem 1992;35:3595-3606.

43 Manabe H, Murakami Y, El-Aasr M, Ikeda T, Fujiwara Y, Ono M, Nohara T: Content variations of the tomato saponin esculeoside $\mathrm{A}$ in various processed tomatoes. J Nat Med 2011; 65:176-179.

44 Fujiwara Y, Kiyota N, Hori M, Matsushita S, Iijima Y, Aoki K, Shibata D, Takeya M, Ikeda T, Nohara T, Nagai R: Esculeogenin A, new tomato sapogenol, ameliorates hyperlipidemia and atherosclerosis in ApoE-deficient mice by inhibiting ACAT. Arterioscler Thromb Vasc Biol 2007;27:2400-2406.

-45 Yang JB, Duan ZJ, Yao W, Lee O, Yang L, Yang XY, Sun X, Chang CC, Chang TY, Li BL: Synergistic transcriptional activation of human Acyl-coenzyme A: cholesterol acyltransterase-1 gene by interferon-gamma and all-trans-retinoic acid THP-1 cells. J Biol Chem 2001;276:20989-20998.

46 Maung K, Miyazaki A, Nomiyama H, Chang CC, Chang TY, Horiuchi S: Induction of acyl-coenzyme A: cholesterol acyltransferase-1 by 1,25-dihydroxyvitamin $\mathrm{D}(3)$ or 9-cis-retinoic acid in undifferentiated THP1 cells. J Lipid Res 2001;42:181-187.

47 Napolitano M, De Pascale C, Wheeler-Jones C, Botham KM, Bravo E: Effects of lycopene on the induction of foam cell formation by modified LDL. Am J Physiol Endocrinol Metab 2007;293:1820-1827.

48 Napolitano M, Avanzi L, Manfredini S, Bravo E: Effects of new combinative antioxidant FeAOX-6 and alpha-tocotrienol on macrophage atherogenesis-related functions. Vascul Pharmacol 2007;46:394-405. 
-49 Hu MY, Li YL, Jiang CH, Liu ZQ, Qu SL, Huang YM: Comparison of lycopene and fluvastatin effects on atherosclerosis induced by a high-fat diet in rabbits. Nutrition 2008;24:1030-1038.

-50 Verghese M, Richardson JE, Boateng J, Shackelford LA, Howard C, Walker LT, Chawan CB: Dietary lycopene has a protective effect on cardiovascular disease in New Zealand male rabbits. J Biol Sci 2008;8:268-277.

-51 Frederiksen H, Rasmussen SE, Schrøder M, Bysted A, Jakobsen J, Frandsen H, RavnHaren G, Mortensen A: Dietary supplementation with an extract of lycopene-rich tomatoes does not reduce atherosclerosis in Watanabe Heritable Hyperlipidemic rabbits. Br J Nutr 2007;97:6-10.

52 Tanzawa K, Shimada Y, Kuroda M, Tsujita Y, Arai M, Watanabe H: WHHL-rabbit: a low density lipoprotein receptor-deficient animal model for familial hypercholesterolemia. FEBS Lett 1980;25;118:81-84.

53 Lorenz M, Fechner M, Kalkowski J, Fröhlich K, Trautmann A, Böhm V, Liebisch G, Lehneis S, Schmitz G, Ludwig A, Baumann G, Stangl K, Stangl V: Effects of lycopene on the initial state of atherosclerosis in New Zealand White (NZW) rabbits. PLoS One 2012; 7:e30808.

54 Mulkalwar SA, Munjal NS, More UK, More B, Chaudhari AB, Dewda PR: Effect of purified lycopene on lipid profile, antioxidant enzyme and blood glucose in hyperlipidemic rabbits. Am J Pharm Tech Res 2012;2:461470.

55 Basuny AM, Gaafar AM, Arafat SM: Tomato lycopene is a natural antioxidant and can alleviate hypercholesterolemia. Afr J Biotechnol 2009;8:6627-6633.
56 Kuhad A, Sharma S, Chopra K: Lycopene attenuates thermal hyperalgesia in a diabetic mouse model of neuropathic pain. Eur J Pain 2008;12:624-632.

57 Hassan HA, Edrees GM: Therapeutic effect of lycopene-rich tomato juice on cardiac disorder in rats fed on fried food in oxidized frying oil. Egypt J Hosp Med 2004;14:115126.

58 Arab L, Steck S: Lycopene and cardiovascular disease. Am J Clin Nutr 2000;71:1691S1695 S.

59 Heber D, Lu QY: Overview of mechanisms of action of lycopene. Exp Biol Med (Maywood) 2002;227:920-923.

60 Verschuren L, Wielinga PY, van Duyvenvoorde W, Tijani S, Toet K, van Ommen B, Kooistra T, Kleemann R: A Dietary Mixture Containing Fish Oil, Resveratrol, Lycopene, Catechins, and Vitamins E and C Reduces Atherosclerosis in Transgenic Mice. J Nutr 2011;141:863-869.

61 Sahin N, Sahin K, Onderci M, Karatepe M, Smith MO, Kucuk O: Effects of dietary lycopene and vitamin E on egg production, antioxidant status and cholesterol levels in Japanese quail. Asian-Aust J Anim Sci 2006;19: 224-230.

62 Misra R, Mangi S, Joshi S, Mittal S, Gupta SK, Pandey RM: LycoRed as an alternative to hormone replacement therapy in lowering serum lipids and oxidative stress markers: randomized controlled clinical trial. J Obstet Gynaecol Res 2006;32:299-304.

-63 Silaste ML, Alfthan G, Aro A, Kesäniemi YA, Hörkkö S: Tomato juice decreases LDL cholesterol levels and increases LDL resistance to oxidation. Br J Nutr 2007;98:12511258 .
64 Ried K: Protective effect of lycopene on serum cholesterol and blood pressure: metaanalyses of intervention trials. Maturitas 2011;68:299-310

65 Rao AV, Agarwal S: Bioavailability and in vivo antioxidant properties of lycopene from tomato products and their possible role in the prevention of cancer. Nutr Canc 1998;31: 199-203.

66 Hadley CW, Clinton SK, Schwartz SJ: The consumption of processed tomato products enhances plasma lycopene concentrations in association with a reduced lipoprotein sensitivity to oxidative damage. J Nutr 2003;133: 727-732.

-67 Agarwal S, Rao AV: Tomato lycopene and low density lipoprotein oxidation: a human dietary intervention study. Lipids 1988;33: 981-984.

68 Engelhard YN, Gazer B, Paran E: Natural antioxidants from tomato extract reduce blood pressure in patients with grade-1 hypertension: a double blind, placebo-controlled pilot study. Am Heart J 2006;151:100.e1-100.e6.

-69 Collins JK, Arjmandi BH, Claypool PL, Perkins-Veazie P, Baker RA, Clevidence BA: Lycopene from two food sources does not affect antioxidant or cholesterol status of middleaged adults. Nutr J 2004;3:15-22.

70 Bose KSC, Agrawal BK: Effect of lycopene from cooked tomatoes on serum antioxidant enzymes, lipid peroxidation rate and lipid profile in coronary heart disease. Singapore Med J 2007;48:415-420. 